\title{
Update and clinical highlights presented at the 2017 American Society of Hematology Meeting
}

\author{
Daniel Heintel
}

Received: 2 May 2018 / Accepted: 22 May 2018 / Published online: 1 June 2018

(c) Springer-Verlag GmbH Austria, part of Springer Nature 2018

At the 2017 American Society of Hematology (ASH) meeting partly standards-changing data in the treatment of hematological malignancies were presented. More than 5000 scientific abstracts are submitted each year and more than 3000 abstracts are accepted for oral and poster presentations through an extensive peer review process. In this issue of memo five hematologists summarized their personal highlights in their respective areas of expertise.

My personal highlight was the presentation of the MURANO study. The clear superiority of a targeted therapy changes practical behavior with immunechemotherapy having no place in second-line treatment of chronic lymphocytic leukemia (CLL) anymore. Moreover, the authors summarize important data about the combination of venetoclax and ibrutinib.

In addition to CLL, reviews about important developments in the treatment of indolent lymphoma, multiple myeloma, CML, and AML are provided in this series.

Concerning indolent lymphoma, Dr. Gilles Salles presented a 10-year update of the PRIMA trial, confirming a progression-free survival (PFS) benefit for rituximab maintenance following R-CHOP induction. The median PFS was 10.5 vs. 4 years $(p<0.0001)$.

Also in mantle cell lymphoma, the superiority of rituximab maintenance was proven.

In fit patients with multiple myeloma, eligible for autologous stem cell transplantation, new induction regimens showed high minimal residual disease negativity rates.

Regarding CML interesting data regarding novel TKIs or treatment duration of imatinib were presented.

In the treatment of AML novel promising substances enrich the spectrum of therapy choices which also impressed the audience at the last ASH meeting.

Conflict of interest D. Heintel receives honoraria from Abbvie, Celgene, Gilead, Janssen, MSD, Roche, Takeda.

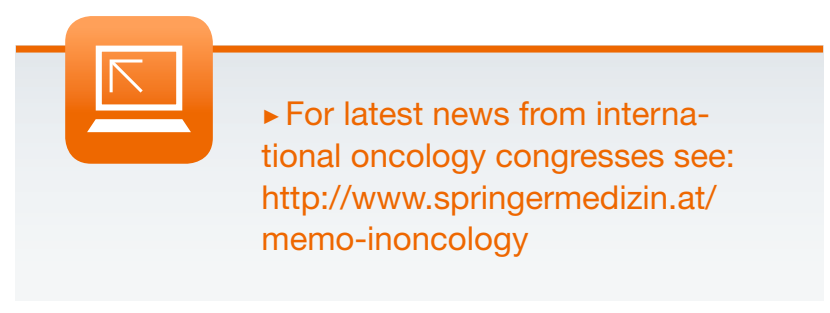

